\title{
Awareness, knowledge about Human papillomavirus and attitude towards its vaccine among university students: A Bangladeshi pilot study
}

\author{
Md. Estiar Rahman*, Mst. Sabrina Moonajilin, Md. Sajan Bishwas, Rajon Banik, Guliva Nazneen Pinky, \\ Sayma Islam Alin
}

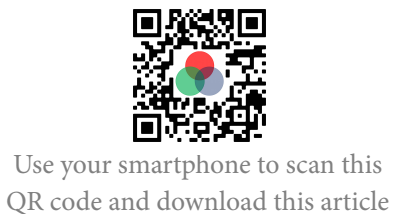

Department of Public Health and Informatics, Jahangirnagar University, Savar, Dhaka-1342, Bangladesh

\section{Correspondence}

Md. Estiar Rahman, Department of Public Health and Informatics, Jahangirnagar University, Savar, Dhaka-1342, Bangladesh

Email: estiarju@gmail.com

History

- Received: 2019-09-25

- Accepted: 2019-11-12

- Published: 2019-12-04

DOI : 10.15419/ajhs.v5i2.458

\section{Check for updates}

\section{Copyright}

( ) Biomedpress. This is an openaccess article distributed under the terms of the Creative Commons Attribution 4.0 International license.

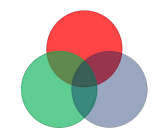

BioMedPress

The Open Access Publisher

\begin{abstract}
Objectives: This study aimed to assess the level of awareness and knowledge regarding HPV infection and attitude towards HPV vaccination among the students of Jahangirnagar University (Dhaka, Bangladesh). Methods: A cross-sectional study was conducted in a random sample of 400 students recruited from different disciplines of the University. A self-administered (paper-and-pencil) questionnaire was used to collect data. Results: Among the participants, 177 (44.3\%) were males, and 134 (33.5\%) were studying in biology disciplines (mean \pm SD of age: $21.46 \pm 1.93$ years). While assessing awareness of HPV, over $60 \%$ (257) students reported that they had already heard of HPV (human papillomavirus). In terms of demographic variables, findings revealed that 'being female', 'being Graduate', and 'being students of biology disciplines' were found to be significant predictors of students' higher level of HPV awareness. Among those aware of HPV, detailed knowledge gaps regarding HPV infection were observed. Only less than half (38.5\%) knew that HPV does not show any symptoms and nearly 33\% of students were aware that both men and women can get HPV infection. Less than half (47.9\%) correctly identified genital skin-to-skin as a mode of transmission. About $42 \%$ of students were knowledgeable about the causative relationship between HPV and genital warts, but a few (36.2\%) knew that HPV infection may lead to the development of penile cancer. In terms of prevention, only $40.2 \%$ knew that the vaccine is a preventive measure of HPV. Only 3.5\% ( $n=14$ ) of the students (females, $n=14$ and males, $n=00$ ) reported to be vaccinated against HPV. Lack of information about the vaccine (53.4\%) had been reported as the main reason for not being vaccinated. The modest percentage (59.33\%) showed their willingness to get the HPV vaccine. Gender, education level, and marital status were three main factors found influencing students' willingness to receive the vaccine. Conclusion: The results of the study revealed that students were aware of HPV, but detailed knowledge about the infection was poor. Students had a poor understanding of the modes of transmission, health problems associated with HPV and prevention of HPV. Health educational programs can be organized to increase knowledge and awareness about HPV infection.
\end{abstract}

Key words: Attitude, Awareness, HPV vaccine, Human papillomavirus, Knowledge

\section{INTRODUCTION}

Human papilloma virus (HPV) presents a significant threat to public health, the most common sexually transmitted infection in the world ${ }^{1} \cdot$ Most sexually active men and women are at risk of being infected by $\mathrm{HPV}$ at some point in their life. Being sexually active increases the risk of being infected by it ${ }^{2}$. Most infections are cleared by the body's immune system automatically, but persistent infection with certain high risk strains of HPV causes a wide range of clinical problems in humans ${ }^{3}$. Over 100 types of HPV have been identified, of these two high risk types HPV 16 and 18 causes cervical, vaginal, and vulvar cancers in women and penile cancer in men and types 6 and 11 causes genital warts in both sexes ${ }^{4,5}$. According to WHO, cervical cancer is the fourth most common cancer in women, accounts for 0.31 million deaths in 2018 globally and about $90 \%$ of deaths are in low and middle-income countries ${ }^{6,7}$. In Bangladesh, cervical cancer has been ranked as the second most common form of cancer among women with over 6,000 deaths and approximately 12,000 new cases per year ${ }^{6}$. Worldwide, three vaccines for HPV are available: bivalent, quadrivalent, and nonavalent. All three vaccines are found to be effective for the prevention of infection with types 16 and 18 that most commonly cause cervical cancer and types 6 and 11 that cause most genital warts ${ }^{8}$. The WHO has endorsed the HPV vaccine as the prime approach to reduce the burden of HPV-related morbidities. Vaccination can be 
started as early as age 9 as recommended by the Centre for Disease and Control (CDC). Males and females can receive the vaccine until the ages of 21 and 26 , respectively ${ }^{9}$.

In Bangladesh, the HPV vaccines have been available since $2016^{10}$. However, the uptake of the vaccine is still poor. Lack of knowledge about different aspects of HPV infection may be a reason. In addition to knowledge, people's attitudes toward vaccination may be relevant. Understanding people's knowledge and attitude towards HPV infection and vaccination may facilitate to design of effective strategies and interventions in raising awareness and encouraging the uptake of the vaccine among the target population. Previous studies on knowledge and attitudes towards HPV infection and vaccination has focused on women in Bangladesh ${ }^{11,12}$. However, there is a lack of research that explores young adult's knowledge and attitude towards HPV infection and vaccination. To the best of our knowledge, there is still no study conducted among young adults of both sexes in Bangladesh, which assess their knowledge and attitude towards HPV infection and HPV vaccination. We may assume that university students are adult enough to adopt medical decisions, including receiving a vaccination, without parental knowledge or consent. Therefore, the present study attempts to generate information about knowledge and attitude towards HPV infection and vaccination among students of a major university in Bangladesh, where students come from different parts of the country. The findings of the study are expected to provide the baseline knowledge and attitude of young adults, who might be at risk of HPV and can help in further prevention of HPV-related diseases.

\section{METHODS}

\section{Study design}

A cross-sectional 'paper-and-pencil' survey was conducted among students at Jahangirnagar University (Dhaka, Bangladesh) during February and March 2019. The institutional review board approved the study of the university. The students were well informed about the purpose of the study, and their formal written consent was obtained before participating in the survey. The participation was voluntary, and all their information was kept anonymous. The only criterion for inclusion was that participants were required to be enrolled in a regular program (Bachelor's and/or Master's) in the university. Those who were not willing to participate were excluded from this study. For this study, the sample size was calculated using an automated software programme, Raosoft sample size calculator ${ }^{13}$. The estimated sample size was based on total students enrolled in the regular program of the university $(\mathrm{N}=15,000)$. At $95 \%$ confidence interval (CI) and 5\% margin of error with $50 \%$ response distribution, the estimated sample size was 375 . The sample size was further rounded off $(\mathrm{N}=$ 400) to overcome errors and increase the reliability of the results. A simple random technique was adopted in selecting students from each faculty. A set of questionnaires in paper format was distributed to students in classes, libraries, university cafes, and hostels. The questionnaire was self-administered (paper-andpencil) and about 30 minutes were taken for completion. After completion, the questionnaires were collected back. The students were given no incentives to participate in the survey.

\section{Study tool}

After preliminary observations and review of literature, a set of questionnaires had been developed, the majority of which had been drawn from previous studies ${ }^{14-16}$. The questionnaire was translated into Bangla and then translated back to English by a different person to assess validity. It was pilot-tested in a sample of 30 university students to ensure the level of validity and degree of repeatability. The questionnaire was designed to collect data on the university students in four areas: (1) Socio-demographic characteristics, (2) Awareness of HPV and source of information, (3) Knowledge about HPV, and (4) Attitude towards HPV vaccination. Socio-demographic characteristics included age, gender, education level, the field of study, marital status and religion. Awareness of HPV was determined by the question "Before today, have you ever heard of HPV?" This question had two options: 'yes' or 'no'. Only those who responded positively for having heard of HPV were asked to complete the knowledge related questions. Five items were used to assess general knowledge about HPV. Furthermore, three items were used to explore respondents' knowledge about the mode of transmission, health problems associated with HPV infection and prevention of HPV. All the knowledge items had a multiple answer format. For items regarding their knowledge, respondents were asked to provide answers with options for 'true,' 'false', and 'do not know' The option of "don't know" is considered as an incorrect answer. Student's attitude towards HPV vaccination was assessed using five items, of those two items had a multiple answer format. The attitude items had two possible options: 'yes' or 'no'. 
Table 1: Demographic profiles of the respondents participated in the study $(n=400)$

\begin{tabular}{lll}
\hline Variables & Frequency & Percentage (\%) \\
\hline Age, years (Mean \pm SD) & $21.5 \pm 1.93$ & \\
Gender & & \\
Male & 177 & 44.3 \\
Female & 223 & 55.7 \\
Education level & & \\
Undergraduate & 231 & 57.8 \\
Graduate & 169 & 42.2 \\
Field of study & & \\
Non-biology & 266 & 66.5 \\
Biology & 134 & 33.5 \\
Marital status & & \\
Single & 370 & 92.5 \\
Married & 30 & 7.5 \\
Religion & & 5.7 \\
Muslim & 377 & \\
Non-Muslim & 23 & \\
\hline
\end{tabular}

Table 2: HPV awareness among the res pondents participated in the study

\begin{tabular}{ll}
\hline Question & Frequency (\%) \\
\hline Before today, have you ever heard of HPV? & \\
Yes & $257(64.3)$ \\
No & $143(35.7)$ \\
Source of information about HPV $a, b$ & \\
Mass media (i.e., TV, Radio etc.) & $119(46.3)$ \\
Health care provider & $56(21.8)$ \\
Internet/social media (Facebook, You Tube) & $33(12.8)$ \\
Health campaign & $32(12.5)$ \\
Friends/relatives & $31(12.1)$ \\
Self-elaboration (Books) & $14(5.4)$ \\
\hline $\begin{array}{l}\text { Abbreviation: HPV: human papilloma virus } \\
{ }^{a} \text { Assessed among the respondents who heard of HPV } \\
{ }^{b} \text { Multiple responses; therefore the sum of response maynot be always 100\% }\end{array}$
\end{tabular}


Table 3: HPV knowledge of the respondents who had heard of

\begin{tabular}{|c|c|}
\hline Knowledge items & Correctly answered (\%) \\
\hline \multicolumn{2}{|l|}{ General knowledge about $\mathrm{HPV}^{a}$} \\
\hline HPV infection is rare in Bangladesh [False] & $174(67.7)$ \\
\hline Most sexually active men and women may have chance to get HPV at some point [True] & $168(65.4)$ \\
\hline HPV infection is almost asymptomatic [True] & $99(38.5)$ \\
\hline Both men and women can get HPV infection [True] & $87(33.8)$ \\
\hline There is a cure for HPV [False] & $93(36.2)$ \\
\hline \multicolumn{2}{|l|}{ Mode of HPV transmission ${ }^{a}$} \\
\hline Sexual intercourse [True] & $211(82.1)$ \\
\hline Genital skin to skin contact [True] & $123(47.9)$ \\
\hline Needle sharing [False] & $178(69.3)$ \\
\hline Using public toilets [False] & $197(76.6)$ \\
\hline Contaminated foods/drinking [False] & $173(67.3)$ \\
\hline \multicolumn{2}{|l|}{ Health problems caused by HPV ${ }^{a}$} \\
\hline Cervical cancer [True] & $169(65.8)$ \\
\hline Genital warts [True] & $107(41.6)$ \\
\hline HIV/AIDS [False] & $192(74.7)$ \\
\hline Penile cancer [True] & $93(36.2)$ \\
\hline Infertility [True] & $136(52.9)$ \\
\hline \multicolumn{2}{|l|}{ Preventive measures against $\mathrm{HPV}^{a}$} \\
\hline Avoid multiple sex partners [True] & $167(64.9)$ \\
\hline Condom use [True] & $171(66.5)$ \\
\hline Vaccination [True] & $105(40.2)$ \\
\hline Oral contraceptive use [False] & $137(53.3)$ \\
\hline Antibiotics [False] & $99(38.5)$ \\
\hline
\end{tabular}

${ }^{a}$ Multiple responses

\section{Statistical analyses}

Statistical analysis was carried out using Statistical Package for Social Sciences (SPSS, version 22.0, IBM). Percentage, mean and standard deviations were calculated wherever applicable. Frequency distribution tables were used to present the findings. We performed multivariate analysis using logistic binary regression to determine the predictors of the following outcomes of interest: aware of HPV and willingness to receive an HPV vaccine. Odds ratios (ORs) with 95\% confidence intervals (CIs) were used in the logistic regression analyses. A $p$-value of less than or equal 0.05 was considered as statistically significant. $\mathrm{H}$

\section{RESULTS}

A total of 400 students were included in the survey. The mean age of the participants was $21.46 \pm 1.93$ years (range: 18-25). Of all the participants, $44.3 \%$ $(n=177)$ were males and $55.7 \%(n=223)$ were females. Based on their education level, $57.8 \%(n=231)$ were undergraduates and $42.2 \%(n=169)$ were graduate students. The majority (66.5\%) were studying in nonbiology disciplines, and the rest (33.5\%) were in biology discipline. Only $7.5 \%(n=30)$ students were married and 5.7\% ( $\mathrm{n}=23)$ were non-Muslim Table 1.

Out of 400 participants, over $60 \%$ reported that they had heard of the HPV before the day of the survey, mostly through the mass media $(46.3 \%)$. Other reported sources of information were health care 
Table 4: Effects of socio-demographic characteristics on HPV awareness: results of regression analysis

\begin{tabular}{|c|c|c|c|c|c|}
\hline \multirow[t]{2}{*}{ Characteristics } & \multirow{2}{*}{$\begin{array}{c}\text { Aware of HPV n } \\
(\%)\end{array}$} & \multicolumn{4}{|c|}{ Odds ratio [95\% CI] } \\
\hline & & Crude Model & p-value & Adjusted Model & p-value \\
\hline \multicolumn{6}{|l|}{ Gender } \\
\hline Male & $103(58.2)$ & Ref. & $<0.05$ & Ref. & $<0.05$ \\
\hline Female & $154(69.1)$ & $1.6[1.06-2.42]$ & & $1.6[1.05-2.59]$ & \\
\hline \multicolumn{6}{|l|}{ Education level } \\
\hline Undergraduate & $136(58.9)$ & Ref. & $<0.05$ & Ref. & $<0.05$ \\
\hline Graduate & $121(71.6)$ & $1.8[1.15-2.69]$ & & $1.5[0.99-2.57]$ & \\
\hline \multicolumn{6}{|l|}{ Field of study } \\
\hline Non-biology & $160(60.2)$ & Ref. & $<0.05$ & Ref. & $<0.05$ \\
\hline Biology & $97(72.4)$ & $1.7[1.12-2.73]$ & & $1.7[1.04-2.72]$ & \\
\hline \multicolumn{6}{|l|}{ Marital status } \\
\hline Single & $236(63.8)$ & Ref. & 0.681 & $1.2[0.53-2.90]$ & 0.632 \\
\hline Married & $21(70.0)$ & $1.3[0.59-2.98]$ & & Ref. & \\
\hline \multicolumn{6}{|l|}{ Religion } \\
\hline Muslim & $239(63.4)$ & Ref. & 0.157 & Ref. & 0.151 \\
\hline Non-muslim & $18(78.3)$ & $2.1[0.76-5.72]$ & & $1.9[0.73-5.69]$ & \\
\hline
\end{tabular}

OR: Odds ratio, CI: Confidence interval

provider $(21.8 \%)$, internet/ social media (12.8\%), health campaign $(12.5 \%)$, friends/relatives $(12.1 \%)$ and self elaboration (Books) (5.4\%) (Table 2). The regression analysis revealed that female gender (Ad $\mathrm{OR}=1.6,95 \% \mathrm{CI}=[1.05-2.59], \mathrm{p}<0.05)$, education level graduate $(\mathrm{Ad} \mathrm{OR}=1.5,95 \% \mathrm{CI}=[0.99-2.57]$, $\mathrm{p}<0.05)$ and field of study biology (Ad OR=1.7, 95\% $\mathrm{CI}=[1.04-2.72], \mathrm{p}<0.05)$ were associated with having higher levels of awareness of HPV Table 4.

The students who had never heard of HPV before were excluded from the knowledge assessment section. Among the 257 participants who had heard of HPV, about $68 \%(n=174)$ correctly stated that HPV infection is not rare in Bangladesh. 65.4\% $(n=168)$ respondents knew that most sexually active men and women might have the chance to get HPV at some point. Less than half (38.5\%) of respondents knew that HPV infection is almost asymptomatic. Onethird said correctly that both men and women can get HPV infection. About 36\% ( $n=93)$ respondents stated correctly that there is no cure for HPV. While exploring the knowledge of students regarding modes of transmission, the majority (82.1\%) correctly identified sexual intercourse as a mode of transmission, and almost half of the respondents (47.9\%) correctly identified genital skin-to-skin contact. Some participants erroneously stated that HPV spreads through needle sharing, use of public toilets and contaminated foods/drinking. When asked about the health problems caused by HPV, nearly two-third correctly identified cervical cancer and more than half (52.9\%) correctly identified infertility. Genital warts and penile cancer were selected correctly by $41.6 \%$ and $36.2 \%$ of respondents, respectively. About $75 \%(n=192)$ of respondents knew that HIV/AIDS is not caused by HPV. When asked about preventive measures, about $65 \%$ and $78 \%$ of respondents correctly stated that HPV could be prevented by the avoidance of multiple sex partners and condom use, respectively. Less than half (40.2\%) knew that the vaccine is a preventive measure. About $53 \%(n=137)$ and only $38.5 \%(n=99)$ knew that HPV could not be prevented by oral contraceptives and antibiotics, respectively Table 3.

In this study, students were considered vaccinated, who had received at least one dose of the HPV vaccine. Among the participants, only $3.5 \%(n=14)$ were reported to be received at least one dose of the HPV vaccine, of these 14 females and no males received the vaccine yet. When asked about reasons for not taking the vaccination, the majority stated they did not know 
Table 5: Attitude towards HPV vaccination of the respondents participated in the study

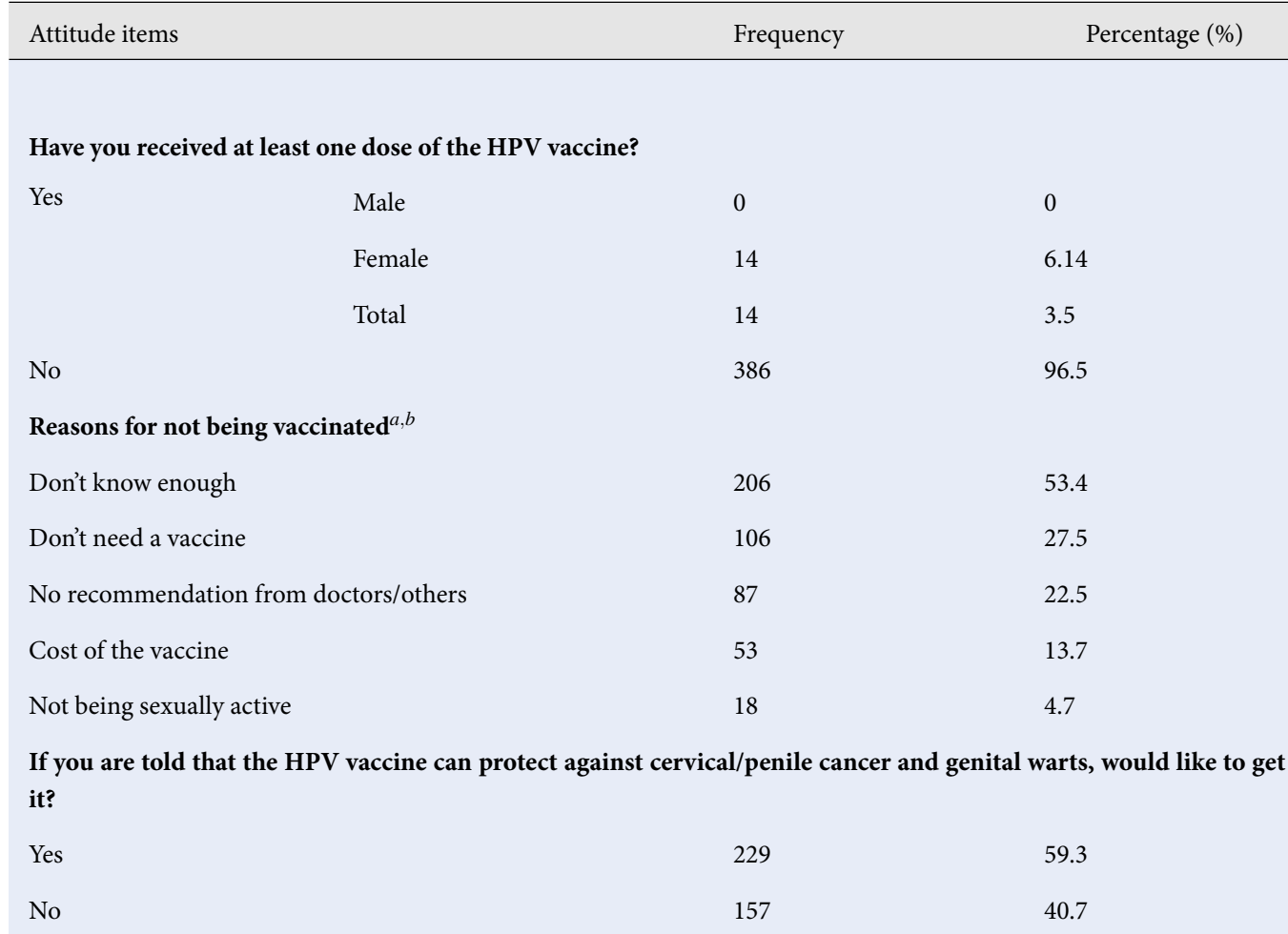

If the HPV vaccine is available and deliverable in the places listed below, where would you prefer to get vaccinated against HPV?

University medical centre

$213 \quad 55.2$

Public hospitals

97

25.1

Private hospitals

41

10.6

No preference

8

2.1

If you are told that the HPV vaccine can protect against cervical/penile cancer and genital warts, would like to recommend it to others (friends/family)?

$\begin{array}{lll}\text { Yes } & 238 & 59.5\end{array}$

No

162

40.4

${ }^{a}$ Assesses among the respondents who didn't get the vaccine

${ }^{b}$ Multiple responses; therefore the sum of response may not be always $100 \%$

enough about vaccination (53.4\%), some (27.5\%) believed that they did not need the vaccine. Other reported reasons were no recommendation from doctors/care givers $(22.5 \%)$, cost of the vaccine (13.7\%), and not being sexually active (4.7\%). Among the students who remain unvaccinated, nearly sixty percent of study participants showed interest in receiving HPV vaccination in the future. More than half (55.2\%) would prefer to get the vaccine at the university medical centre. The majority of the respondents (59.5\%) said they would have recommended the vaccine to friends/relatives if they were told that it could protect against cervical/penile cancer and genital warts Table 5.

With regard to willingness in receiving $\mathrm{HPV}$ vaccination, gender female $(\mathrm{Ad} \mathrm{OR}=3.3,95 \% \mathrm{CI}=[2.02$ 4.97], $\mathrm{p}<0.05)$, education level graduate $(\mathrm{Ad} \mathrm{OR}=1.4$, $95 \% \mathrm{CI}=[1.02-2.37], \mathrm{p}<0.05)$ and marital status mar$\operatorname{ried}(\mathrm{Ad} \mathrm{OR}=3.4,95 \% \mathrm{CI}=[1.09-9.97], \mathrm{p}<0.05)$ were significantly associated with higher willingness to get the vaccine Table 6. 
Table 6: Association of socio-demographic characteristics with willingness to be vaccinated of the respondents

\begin{tabular}{|c|c|c|c|c|c|}
\hline \multirow[t]{2}{*}{ Characteristics } & \multirow{2}{*}{$\begin{array}{l}\text { Willing to be } \\
\text { vaccinated }^{a} \mathrm{n} \\
(\%)\end{array}$} & \multicolumn{4}{|c|}{ Odds ratio $[95 \% \mathrm{CI}]$} \\
\hline & & Crude Model & p-value & Adjusted Model & p-value \\
\hline \multicolumn{6}{|l|}{ Gender } \\
\hline Male & $74(43.5)$ & Ref & $<0.05$ & Ref & $<0.05$ \\
\hline Female & $155(71.8)$ & $3.3[2.16-5.04]$ & & $3.3[2.02-4.97]$ & \\
\hline \multicolumn{6}{|l|}{ Education level } \\
\hline Undergraduate & $122(54.5)$ & Ref & $<0.05$ & Ref & $<0.05$ \\
\hline Graduate & $107(66.1)$ & $1.6[1.07-2.47]$ & & $1.4[1.02-2.37]$ & \\
\hline \multicolumn{6}{|l|}{ Field of study } \\
\hline Non-biology & $146(56.4)$ & Ref & 0.092 & Ref & 0.089 \\
\hline Biology & $83(65.4)$ & $1.5[0.94-2.27]$ & & $1.3[0.92-2.19]$ & \\
\hline \multicolumn{6}{|l|}{ Marital status } \\
\hline Single & $210(57.8)$ & Ref. & $<0.05$ & Ref. & $<0.05$ \\
\hline Married & $19(82.6)$ & 3.5 [1.15-10.37] & & 3.4 [1.09-9.97] & \\
\hline \multicolumn{6}{|l|}{ Religion } \\
\hline Muslim & $228(61.6)$ & Ref & 0.567 & Ref & 0.523 \\
\hline Non-muslim & $11(68.7)$ & $3.4[0.47-4.03]$ & & $3.2[0.41-3.92]$ & \\
\hline
\end{tabular}

${ }^{a}$ Included only those still not receive HPV vaccination

\section{DISCUSSION}

This present study was conducted to assess knowledge and awareness of HPV infection and attitude towards HPV vaccination of students of a major university in Bangladesh. To the best of author's knowledge, this is the first study of its kind conducted among young adults in Bangladesh. The findings of this study reported that more than 6 out of every 10 participants were aware of HPV (Table 2). The level of awareness among university students of this study was higher than the level of awareness (56.6\%) among urban women in Bangladesh ${ }^{12}$. It was expected since the study was conducted among university students. Exposure to information on HPV, as well as associated advertising and health campaigns, may likely be an influencing factor for this finding. The primary source of HPV information was Mass media (i.e., TV, Radio, etc.). This finding was consistent with previous studies ${ }^{17-20}$. Mass media like TV, Radio serves as a popular source of entertainment and is commonly utilized by young adults for leisure. They can be a means of disseminating information on HPV infection and the HPV vaccine.
Greater awareness, however, does not always imply correct knowledge. This study demonstrated that detailed knowledge of HPV infection among the students aware of HPV was poor, with the exception of a few questions. At the early stage of infection, HPV usually shows no symptoms ${ }^{18}$. In the present study, less than half (38.5\%) of the students knew that HPV does not show any symptoms. HPV infection affects both men and women ${ }^{21}$. Only $33.2 \%$ of students were aware that HPV affects both genders, and almost the same number of students knew that there is no cure for HPV (Table 3). When asked questions regarding the modes of transmission, the majority correctly identified sexual intercourse as a mode of transmission, but less than half (47.9\%) correctly identified genital skin-to-skin. In addition, the students also erroneously reported that HPV spreads through needle sharing, the use of public toilets and contaminated foods/drinking (Table 3). HPV causes a wide range of clinical problems in human including cervix cancer, genital warts and penile cancer ${ }^{20,21}$. Most of the students participated in this study were knowledgeable about the causative relationship between HPV and cervical cancer, but not of that between HPV and 
genital warts or penile cancer. One possible reason for this is that health programs designed to create awareness regarding HPV, the emphasis might have been on the causative relationship between HPV and cervical cancer rather than any other association. When students were asked questions regarding the preventive measures of HPV, a severe lack of knowledge was observed. For instance, less than half of the students (40.2\%) knew that the vaccine is a preventive measure of HPV. Moreover, only $38.5 \%$ knew that HPV cannot be prevented by antibiotics (Table 3 ). These findings are much poorer than in studies conducted in other countries $^{22,23}$.

Among the socio-demographic variables examined, gender, education level and field of study were significantly associated with HPV awareness (Table 4). Female students had a higher awareness of HPV than males. This finding is consistent with previous findings ${ }^{2,24-26}$. Cervical cancer is a common form of cancer among women ${ }^{27}$ and is primarily caused by $\mathrm{HPV}^{21}$; it is not surprising that females are more likely to have heard of HPV than males. Awareness of HPV among students enrolled in biology disciplines was higher compared to those in non-biology disciplines. This finding agrees with previous studies ${ }^{24,28}$. Students studying subjects related to healthcare might have learned about HPV and would have acquired more knowledge about it. Graduate students reported a higher level of HPV awareness compared to undergraduates. This may be plausible due to the higher proportion of graduate students from biology disciplines and/or the female gender.

Our results indicate that the percentage of students got vaccinated was extremely low (3.5\%). Moreover, no male students had received the vaccine (Table 5). This was quite surprising since the study was conducted among students in a tertiary level educational institution. It was expected that they would be more concern about their health. Previous studies from some Asian countries like India, Hong Kong reported a higher vaccination rate compared to this finding, which ranged from $6.1 \%$ to $13.3 \%$ among university students ${ }^{28,29}$. This finding warrants a health education program focusing on the benefits of the HPV vaccine conducted among students to increase the uptake of the vaccine. Lack of information on HPV vaccine $(53.4 \%)$ had been reported as the main reason for not being vaccinated (Table 5). This was also reported by previous studies ${ }^{30,31}$. As knowledge about the vaccine is associated with acceptance or rejection of the vaccine, it is important to overcome knowledge deficits through educational efforts. It is important to note that our study was conducted at about
3 years after the release of the HPV vaccine in our market. Lack of media publicity about the HPV vaccine may be a contributing factor to this finding. The present study has shed light on interest among university students in receiving the HPV vaccine. Among the students who were still not vaccinated, the modest percentage (59.33\%) showed their willingness to vaccination. The modest intention might be related to the lack of enough knowledge. Another reason why an individual might be reluctant to receive the HPV vaccine is that getting vaccinated against HPV would mean that they were sexually active. Among the socio-demographic variables, gender, education level, and marital status were significantly associated with HPV vaccination willingness (Table 6). Females seemed to have more willingness to receive the vaccine than their counterparts. This was consistent with previous studies ${ }^{27,28}$. The low interest of the male students may be partially attributed to the focus mostly given to cervical cancer in the educational efforts of HPV and thus, information such as the prevention of penile, anal, and oropharyngeal cancer might have overlooked. Graduate students had a higher willingness to receiving the vaccine than undergraduates. In general, students who got higher education become more conscious about their health and show greater interest in preventive measures like vaccination. The students who got married had a higher willingness to receive the vaccine than others. HPV is primarily associated with sexual activity ${ }^{32}$. It is not surprising that the married public showed more interest in receiving the vaccine. The risk of acquiring HPV infection increases soon after becoming sexually active ${ }^{33}$. The health regularity bodies recommend adopting the HPV vaccine before sexual initiation ${ }^{9}$. There is a need to create more awareness about HPV and the government should arrange more HPV vaccination programs.

\section{CONCLUSION}

From this study, it has been revealed that students were aware of HPV infection, but knowledge regarding different aspects of the infection was poor. They had a poor understanding of the modes of transmission, associated health problems, and the prevention of HPV. Moreover, the vaccination rate among students was extremely low and a modest percentage showed their willingness to receive the vaccine. Knowledge about the modes of transmission, associated health problems and prevention might be associated with acceptance or rejection of HPV vaccination; it is essential to increase knowledge about HPV. 
Health educational programs can be organized to increase knowledge about HPV infection among students in the university setting in Bangladesh.

\section{STRENGTHS AND LIMITATIONS OF THE STUDY}

This is perhaps the first study that attempts to assess university students' knowledge and awareness of HPV infection and their attitude towards HPV vaccination in Bangladesh. This study provides unique population-based information regarding HPV which can be utilized to design effective health programs to create awareness and acts as baseline information regarding HPV of young adults. Besides the strengths, this study has few limitations. As all participants were from one university in Bangladesh, the findings of this study might not be generalized for students of other universities/ young adults' population of the country. Therefore, future studies comprising of the more significant sample should be directed. One further limitation of this study might lie in the self-reported data which involves some risk of recall bias. In conclusion, uptake and acceptance of the HPV vaccine must be enhanced among young adults in this country, through increased awareness and education on HPV.

\section{CONFLICT OF INTEREST}

All authors declare that they have no conflicts of interest.

\section{ACKNOWLEDGMENT}

The study was not supported in whole or in part by any funding source. We acknowledge the contribution of our team members. We are grateful to all students who voluntarily participated in this survey.

\section{REFERENCES}

1. World Health Organization. Weekly epidemiological record Número 19. 2017;(19):241-268; 2017. Available from: https: //www.who.int/wer/2017/wer9219/en/。

2. Blödt S, Holmberg C, Müller-Nordhorn J, Rieckmann N. Human Papillomavirus awareness, knowledge and vaccine acceptance: a survey among 18-25 year old male and female vocational school students in Berlin, Germany. Eur J Public Health. 2012;22(6):808-13. PMID: 22199161. Available from: $10.1093 /$ eurpub/ckr188.

3. Colón-López V, Ortiz AP, Palefsky J. Burden of human papillomavirus infection and related comorbidities in men: implications for research, disease prevention and health promotion among Hispanic men. P R Health Sci J. 2010;29(3):232-40. PMID: 20799510.

4. Walboomers JM, Jacobs MV, Manos MM, Bosch FX, Kummer JA, Shah KV, et al. Human papillomavirus is a necessary cause of invasive cervical cancer worldwide. J Pathol. 1999;189(1):12-9. PMID: 10451482. Available from: 10.1002/(SICI)1096-9896(199909)189:1<12:: AID-PATH431>3.0.CO;2-F.
5. Gillison ML, Koch WM, Capone RB, Spafford M, Westra WH, Wu $L$, et al. Evidence for a causal association between human papillomavirus and a subset of head and neck cancers. J Natl Cancer Inst. 2000;92(9):709-20. PMID: 10793107. Available from: 10.1093/jnci/92.9.709.

6. World Health Organization. National Strategy for Cervical Cancer Prevention and Control in Bangladesh, 20172022. http://www.searo.who.int/bangladesh/cervical-cancer -prevention/en/. Published 2018. Accessed May 28, 2019.; 2018.

7. WHO.|Cervical cancer. https://www.who.int/cancer/preventi on/diagnosis-screening/cervical-cancer/en/. Published 2018. Accessed May 28, 2019.; 2018.

8. Human papillomavirus (HPV). https://www.who.int/immuniz ation/diseases/hpv/en/. Accessed September 11, 2019.

9. Centers for Disease Control and Prevention. HPV vaccine information for Clinician fact sheet. 2011:1-. https://www.cdc.g ov/std/hpv/stdfact-hpv-vaccine-young-women.htm; 2011.

10. World Health Organization. HPV vaccine introduced in Bangladesh. SEARO. 2017. http://www.searo.who.int/bangla desh/HPVvaccinelaunch/en/. Accessed May 27, 2019.; 2017.

11. Islam JY, Khatun F, Alam A, Sultana F, Bhuiyan A, Alam N, et al. Knowledge of cervical cancer and HPV vaccine in Bangladeshi women: a population based, cross-sectional study. BMC Womens Health. 2018;18(1):15. PMID: 29325530. Available from: 10.1186/s12905-018-0510-7.

12. Bhuiyan A, Sultana F, Islam JY, Chowdhury MA, Nahar Q. Knowledge and Acceptance of Human Papillomavirus Vaccine for Cervical Cancer Prevention Among Urban Professional Women in Bangladesh: A Mixed Method Study. Biores Open Access. 2018;7(1):63-72. PMID: 29844948. Available from: 10.1089/biores.2018.0007.

13. Sample Size Calculator by Raosoft, Inc. http://www.raosoft.co m/samplesize.html. Accessed May 28, 2019.

14. Giuseppe G, Abbate R, Liguori G, Albano L, Angelillo IF. Human papillomavirus and vaccination : knowledge, attitudes, and behavioural intention in adolescents and young women in Italy. 2008;Available from: 10.1038/sj.bjc.6604454.

15. Patel H, Pcolkina K, Strazdina K. Awareness of HPV infection and attitudes toward HPV vaccination among Latvian adolescents. 2017;Available from: 10.1002/ijgo.12117.

16. Khan TM, Buksh MA, Rehman IU, Saleem A. Knowledge, attitudes, and perception towards human papillomavirus among university students in Pakistan. Papillomavirus Res. 2016;2:122-7. PMID: 29074171. Available from: 10.1016/j.pvr. 2016.06.001.

17. Gerend MA, Magloire ZF. Awareness, knowledge, and beliefs about human papillomavirus in a racially diverse sample of young adults. J Adolesc Health. 2008;42(3):237-42. PMID: 18295131. Available from: 10.1016/j.jadohealth.2007.08.022.

18. Gravitt PE, Winer RL. Natural history of HPV infection across the lifespan: role of viral latency. Viruses. 2017;9(10):1-10. PMID: 28934151. Available from: 10.3390/v9100267.

19. Woodman CB, Collins SI, Young LS. The natural history of cervical HPV infection: unresolved issues. Nat Rev Cancer 2007;7(1):11-22. PMID: 17186016. Available from: 10.1038/ nrc2050.

20. Stone KM. Human papillomavirus infection and genital warts: update on epidemiology and treatment. Clin Infect Dis. 1995;20:91-7. PMID: 7540876. Available from: 10.1093/ clinids/20.Supplement_1.S91.

21. Bosch FX, Lorincz A, Muñoz N, Meijer CJ, Shah KV. The causal relation between human papillomavirus and cervical cancer. J Clin Pathol. 2002;55(4):244-65. PMID: 11919208. Available from: $10.1136 /$ jcp.55.4.244.

22. Davis EN, Doyle SCP. Young Adults' Awareness and Knowledge of Human Papillomavirus, Oropharyngeal Cancer, and the HPV Vaccine. Grad Progr Heal Rehabil Sci. 2015;Available from: http://ir.lib.uwo.ca/etd\%0Ahttp://ir.lib.uwo.ca/etd/3384.

23. Kasymova S, Harrison SE, Pascal C. Knowledge and Awareness of Human Papillomavirus Among College Students in South Carolina. Infect Dis (Auckl). 2019;12:1178633718825077. PMID: 30728723. Available from: 10.1177/1178633718825077. 
24. Rashid S, Labani S, Das BC. Knowledge, awareness and attitude on HPV, HPV vaccine and cervical cancer among the college students in India. PLoS One. 2016;11(11):e0166713. PMID: 27861611. Available from: 10.1371/journal.pone. 0166713.

25. Pitts MK, Heywood W, Ryall R, Smith AM, Shelley JM, Richters J, et al. Knowledge of human papillomavirus (HPV) and the HPV vaccine in a national sample of Australian men and women. Sex Health. 2010;7(3):299-303. PMID: 20719218. Available from: 10.1071/SH09150.

26. Nnodu O, Erinosho L, Jamda M, Olaniyi O, Adelaiye R, Lawson $\mathrm{L}$, et al. Knowledge and attitudes towards cervical cancer and human papillomavirus: a Nigerian pilot study. Afr J Reprod Health. 2010;14(1):95-108. PMID: 20695142.

27. Rathod S, Samal SK, Samal S, Ghose S. Knowledge and Awareness of Cervical Cancer and Human Papilloma Virus Vaccine among Medical Students: A Cross-sectional Study. J South Asian Fed Menopause Soc. 2017;5(1):41-4. Available from: 10.5005/jp-journals-10032-1103.

28. Chiang VC, Wong HT, Yeung PC, Choi YK, Fok MS, Mak OI, et al. Attitude, acceptability and knowledge of HPV vaccination among local university students in Hong Kong. Int J Environ Res Public Health. 2016;13(5):486. PMID: 27187424.
Available from: 10.3390/ijerph13050486.

29. Das EN, Francis PT. HPV vaccine knowledge and coverage among female students in a medical college, Kerala. Int $J$ Community Med Public Heal. 2018;5(12):5133. Available from: 10.18203/2394-6040.ijcmph20184779.

30. Watson-Jones D, Tomlin K, Remes P, Baisley K, Ponsiano R, Soteli $S$, et al. Reasons for receiving or not receiving HPV vaccination in primary schoolgirls in Tanzania: a case contro study. PLoS One. 2012;7(10):e45231. PMID: 23115621. Available from: 10.1371/journal.pone.0045231.

31. Bair RM, Mays RM, Sturm LA, Zimet GD. Acceptability of the human papillomavirus vaccine among Latina mothers. J Pediatr Adolesc Gynecol. 2008;21(6):329-34. PMID: 19064226. Available from: 10.1016/j.jpag.2008.02.007.

32. Kjaer SK, Chackerian B, van den Brule AJ, Svare El, Paull G, Walbomers JM, et al. High-risk human papillomavirus is sexually transmitted: evidence from a follow-up study of virgins starting sexual activity (intercourse). Cancer Epidemiol Biomarkers Prev. 2001;10(2):101-6. PMID: 11219765.

33. Clark S. Early marriage and HIV risks in sub-Saharan Africa. Stud Fam Plann. 2004;35(3):149-60. PMID: 15511059. Available from: 10.1111/j.1728-4465.2004.00019.x. 